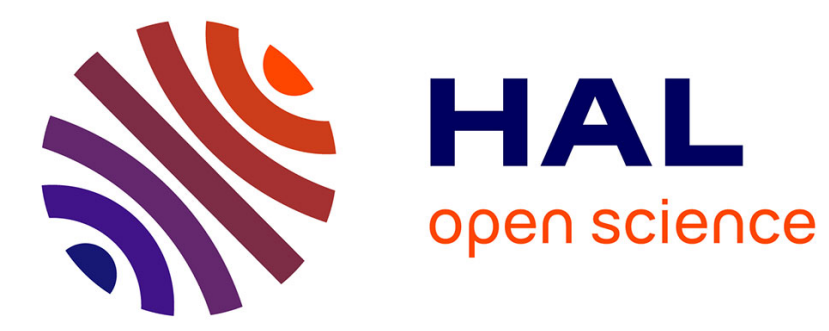

\title{
Smart Planning - Approaching the Characteristics of a Valid, Balanced Transport Round
}

\author{
Virginie Govaere, Liên Wioland, Julien Cegarra, Didier Gourc, Antoine
}

Clément

\section{- To cite this version:}

Virginie Govaere, Liên Wioland, Julien Cegarra, Didier Gourc, Antoine Clément. Smart Planning Approaching the Characteristics of a Valid, Balanced Transport Round. IEA 2018 - 20th Congress of the International Ergonomics Association, Aug 2018, Florence, Italy. pp.387-396, 10.1007/978-3-31996089-0_42 . hal-01896723

\section{HAL Id: hal-01896723 https://imt-mines-albi.hal.science/hal-01896723}

Submitted on 6 Nov 2018

HAL is a multi-disciplinary open access archive for the deposit and dissemination of scientific research documents, whether they are published or not. The documents may come from teaching and research institutions in France or abroad, or from public or private research centers.
L'archive ouverte pluridisciplinaire HAL, est destinée au dépôt et à la diffusion de documents scientifiques de niveau recherche, publiés ou non, émanant des établissements d'enseignement et de recherche français ou étrangers, des laboratoires publics ou privés. 


\title{
Smart Planning - Approaching the Characteristics of a Valid, Balanced Transport Round
}

\author{
Virginie Govaere $^{1(\bowtie)}$, Liên Wioland ${ }^{1}$, Julien Cegarra ${ }^{2}$, Didier Gourc ${ }^{3}$, \\ and Antoine Clément ${ }^{3}$ \\ 1 INRS, Working Life Department, 1 rue du morvan - CS 60027 , \\ 54519 Vandoeuvre Cedex, France \\ \{virginie.govaere, lien.wioland\}@inrs.fr \\ ${ }^{2}$ Université de Toulouse, INU1 Champollion, SCoTE EA7420, Place Verdun, \\ 81100 Albi, France \\ julien.cegarra@univ-jfc.fr \\ ${ }^{3}$ Université de Toulouse - IMT Mines Albi 2, Campus Jarlard, \\ 81013 Albi Cedex 09, France \\ \{didier.gourc, antoine.clement\}@mines-albi.fr
}

\begin{abstract}
Road Freight Transport (RFT) companies represent 37,200 companies and roughly 420,000 employees. This sector is confronted by strong competition and growing pressure from customers and suppliers, tight delivery times, exacerbated flexibility, etc. In parallel, they are required to fulfill performance duties in terms of preventing risks of occupational accidents and diseases. In 2016, CNAM statistics reports 70 deaths per year, 3,000,000 work days lost, an average 6 work days lost per employee, an index of frequency (73\%). The planner builds the transport rounds by integrating at best all dimensions (regulation, economic, environmental and prevention of health and safety of their employees). In this context, the Smart Planning project aims to develop a computer system to help create more balanced planning. The purpose of this paper is to present the first results. It proposes, with an ergonomic analysis, to identify the prescribed and tacit constraints manipulated by the planners in two companies. A questionnaire is drawn up to validate and enrich the data on the health and safety dimension.

This study is not a business case; it is ergonomic analysis to validate different determinants identified (health and safety) and investigates the assessment of these determinants and their possible consideration during planning.
\end{abstract}

Keywords: Prevention of health and safety $\cdot$ Balanced planning Compromise

\section{Introduction}

\subsection{Business Sector Background}

Road Freight Transport (RFT) companies represent an annual turnover of 44 billion euros, which is generated by more than 37,200 companies. This sector is confronted by 
strong competition and growing pressure from customers and suppliers, tight delivery times, exacerbated flexibility, and many other challenges [1]. Financial issues impose additional constraints upon the already complex problem of planning transport operations. Procurement, production and distribution are indeed all organized based on stockless production involving "just-in-time" (JIT) deliveries. In transport terms, this is reflected by smaller freight consignments to be moved at higher frequency for recipients requiring delivery as quickly as possible or even by appointment. Ensuring RFT company survival implies taking these constraints into account by optimizing delivery rounds. RFT companies are also subjected to specific national and community standards and regulations (regulatory and environmental issues). Alternative and combined modes are emerging in rail, sea, river transportation on environmental grounds. However, whatever the energy combination, certain delivery modes are rapidly beset by limits in terms of flexibility, delivery times, customer proximity, etc., and the last kilometers of a journey are necessarily traveled by road. Optimization of the number of kilometers traveled and optimum vehicle selection, based on transport round constraints, are levers for responding to part of the financial and environmental issues. At the same time, companies are committed to fulfilling performance duties in relation to preventing risks of occupational accidents and diseases under Article L4121-1 of the French Labor Code governing occupational health-safety issues. CNAM national health insurance fund statistics and other institute show that the claims ratio in this branch in France remains very much higher than the national average for all branches in that employees are twice as often victims of accidents and of more serious accidents [2, 3]. The commonly identified risks for employees in this sector involve both the physical aspects (musculoskeletal disorders related to handling, falls on the level, exposure to vibration, etc.) and mental aspects (high mental load, activity segmentation, higher pace of work, dealing with unforeseen events, etc.) of the work activity. Multiple research studies and actions have mobilized stakeholders from different areas and have contributed to improving driver safety. Nevertheless, this problem remains an issue. Furthermore, RFT planner activity is performed within a specific context involving segmentation of various operations, performance of dual tasks [4]. Interruptions, segmentations and performance of several tasks in parallel constitute risk factors for the planner and factors that impact on work quality and the compromises to be adopted during planning. These compromises affect driver working conditions: managing an urgent situation in a tense, stressful environment leads operators to protect themselves less and is often associated with increases in accident risk. We defend a dual viewpoint in this paper in order to act upon the sector's claims ratio:

- Integration of the health-safety issues right from delivery round planning stage. Planning stage consideration of the frequency of handling operations to be performed by the driver, of available aids (pallet trucks, bay operators, etc.) and of infrastructures (stairs, lifts, etc.) at the customer, alternation of more and less demanding activity phases or balanced allocation of "difficult" delivery points among drivers may represent a solution to alleviating driver levels of stress.

- Provision of assistance suited to planner activity. This could entail planning support in a context, in which the mental aspects of these employees' work are strongly present. 
Ultimately, it is up to the planner to integrate all the relevant and often antagonistic financial, environmental and social issues, when designing transport rounds. Under these complex conditions full of uncertainty, the planner must adopt a compromise between these constraints. The quality of the compromise depends on the time the planner can give to this operation, on his/her representation of each constraint and on the margins for maneuver available to him/her.

\subsection{Research Context}

Aids to managing transport or Transport Management Systems (TMS) are available to the planner, but these solutions focus only on the financial issues. The Smart Planning project aims to overcome this limitation by integrating financial, environmental and health and safety aspects for both drivers and planners into robust planning aids for transport operations. The project is financed by the ANR and features an interdisciplinary consortium. The primary scientific aim of this project is to model the constraints integrated by the planner in order to propose valid delivery rounds from financial, environmental and social standpoints, while integrating operator (planner and driver) health and safety aspects [5]. The objective is also to model the dynamics of the compromise adopted by the planner which respond differently to both the challenges and the transport company strategy. These models should be subjected to break-down into operational criteria, which can be rated and are: (1) financial, (2) environmental and (3) health and safety-related.

To achieve this primary project aim, a number of stages are unavoidable, including listing and categorizing the constraints to be managed by the planner, defining transport round performance indicators from health and safety, financial and environmental standpoints, identifying constraint prioritization strategies to be adopted by planners, etc. Ergonomic analysis is conducted to identify the planners' constraints (formulated, released or satisfied constraints). The purpose of this paper is to present these results, which contribute to defining the initial components of a valid, balanced transport round in financial, ecological and health and safety terms.

The second project aim is to introduce the approach to validate the list of determinants identified in relation to the health and safety dimension and to investigate rating of these determinants by planners during their work. Preliminary results illustrate the significance of this approach.

\section{Methodology}

The ergonomic analysis involved the two industrial partners of the Smart Planning project. These partners are freight transporters. These SMEs employ 195 and 60 people. Identical methodology was deployed at both companies.

\subsection{Stage 1: Description of Planning Activity}

Analysis of the planning activity was conducted using instrumented observations (video and audio recordings). The video recordings were made using cameras to 
observe two planners/company performing a usual operation during their work shifts. Observation-based data were collected from the start to the end of the work shift on full working days during a single week. This operation provided $24 \mathrm{~h}$ of recordings (2 planners/company on morning and afternoon shifts, excluding breaks, on 3 full working days). The observations were formalized in the form of an activity code, which subsequently enabled us to determine the time and frequency of the operations performed, the various tools used, the communications, the purpose of these communications and the contact persons involved. This analysis was complemented by interviews with participants both directly (planners) and indirectly (operations managers, drivers and general managers) involved in the planning activity. The latter management personnel establishes the company strategy and hence guidelines in terms of planning criterion selection and prioritization). An interview questionnaire was drawn up and systematized. This included 5 main categories of information: constraints related to the client and its requirement, constraints related to human and equipment resources, constraints related to infrastructures and regulations, company guidelines and strategic decisions and the different types of unforeseen events encountered.

\subsection{Stage 2: Constraint Identification and Prioritization}

Following the interviews and observations, we identified the concepts used by the planners for building transport rounds. For the stakeholders, this involved prioritizing characteristics for each concept based on their importance, when planning transport rounds. We collected the verbal accounts concomitant with this prioritization task. A card game was developed for this prioritization exercise; it included the concepts identified during Stage 1 and their characteristics. For example, there was the "vehicle" concept along with its typical attributes: "tailgate present", "bed length" or "side loading possible", etc. At each company, seven employees took part in interviews and prioritization. Data acquisition required a week-long visit to each company.

\subsection{Stage 3: Collection of Sociotechnical System (STS) Determinant Ratings by Sector Professionals}

A questionnaire was edited based on the Stage 1 interview findings and earlier work in the sector [ref lien]. This questionnaire was validated by the project steering committee, tested by the 2 industrial partners ( 7 planners), then circulated online via professional federations within the RFT sector. The purpose of circulation was to generalize the results obtained with the project industrial partners. The questionnaire included the following sections:

- A section identifying the respondent's job and the company profile

- A section describing the planning activity

- A section focusing on factors causing difficulty or arduousness experienced by drivers and their consideration during planning. For each factor, this involved determining its presence or absence in the activity, rating its degree of difficulty or arduousness on a scale of 1 to 10 ( 1 very low and 10 very high) and stating whether this factor is considered during planning. 
Three categories of factor were envisaged in the last section: those causing difficulty or physical arduousness, those causing mental arduousness and those causing emotional arduousness (see Table 1). A free data entry zone for factors complementing this list closed out this section.

Table 1. Example of questioning for each factor category

\begin{tabular}{|c|c|c|c|}
\hline & Physical & Mental & Emotional \\
\hline $\begin{array}{l}\text { Factor } \\
\text { present or } \\
\text { absent }\end{array}$ & $\begin{array}{l}\text { Do you reckon han- } \\
\text { dling is a factor of ar- } \\
\text { duousness in driver } \\
\text { activity? } \\
\text { - Yes } \\
\text { - No }\end{array}$ & $\begin{array}{l}\text { Do you reckon your } \\
\text { drivers encounter } \\
\text { driving situations } \\
\text { that require a high } \\
\text { or prolonged level } \\
\text { of attention? } \\
\text { - Yes } \\
\text { - No }\end{array}$ & $\begin{array}{l}\text { Can the client rela- } \\
\text { tionship be a factor } \\
\text { causing difficulty in } \\
\text { driver activity? } \\
\text { - Very often } \\
\text { - Often } \\
\text { - Sometimes } \\
\text { - Rarely } \\
\text { - Never }\end{array}$ \\
\hline Definition & $\begin{array}{l}\text { Handling: carrying } \\
\text { packages, moving pal- } \\
\text { lets without mechanical } \\
\text { equipment, filming, } \\
\text { sorting, etc. }\end{array}$ & $\begin{array}{l}\text { This may involve } \\
\text { driving at night, } \\
\text { driving electrical } \\
\text { silent vehicles or } \\
\text { maneuvers requir- } \\
\text { ing constant vigi- } \\
\text { lance }\end{array}$ & $\begin{array}{l}\text { Factor related to wel- } \\
\text { coming, assisting or } \\
\text { collaborating, possi- } \\
\text { ble relational difficul- } \\
\text { ties, etc. }\end{array}$ \\
\hline $\begin{array}{l}\text { Rating } \\
\text { (for each } \\
\text { factor) }\end{array}$ & \multicolumn{3}{|c|}{ 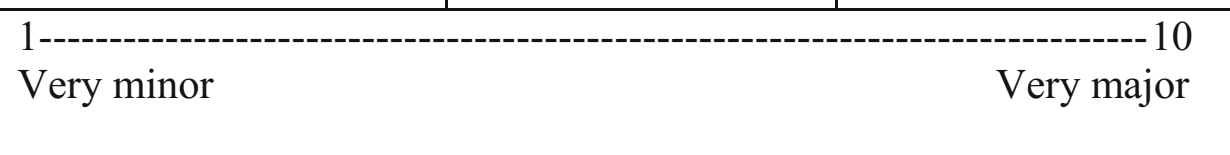 } \\
\hline $\begin{array}{l}\text { Consid- } \\
\text { eration } \\
\text { (for each } \\
\text { factor) }\end{array}$ & \multicolumn{3}{|c|}{$\begin{array}{l}\text { If it exists, do you take this factor into account during planning? } \\
\text { - Yes } \\
\text { - No }\end{array}$} \\
\hline
\end{tabular}

\section{Results}

\subsection{Description of Planning Activity}

The planners managed a client relationship (11\% of operator activity time), available physical and human resources (21\% of activity time) and transport schedules (16\% of activity time). They established the traceability (36\% of activity time) and provided an interface between the different stakeholders (management, clients, drivers, etc.). Comparing activity and operation frequency therefore highlighted the fragmented nature of the planning activity. This activity fragmentation was evidenced by the brevity of the operations as shown by their average times (approximately $1 \mathrm{~min}$. 30 secs. per operation). The planners issued or received oral communications (face-toface or by telephones) for $40 \%$ of the activity time (i.e. $28 \mathrm{~h}$ of communications). 
These communications occurred in parallel with the transport round planning activity. Planning represented $21 \%$ of the planners' total activity time. Typically, it could be divided into collection of data, allocation of resources and optimization of various criteria. Observation of the planning activity revealed a succession of back-and-forth operations on the planned transport round or order addition or deletion.

\subsection{Identification, Categorization and Prioritization of Constraints}

The interviews and card game were run with planners, operations managers and company managers: a total of 14 study participants. The data exhibited no variations in participant status. The interviews and observations revealed that the concepts used by the different players in planning transport rounds were the delivery sites, the vehicles, the client, the order, the driver and the round. These concepts were characterized with attributes. For example, the Site (warehouse, store, private individual) was characterized with address, loading location, unloading location, delivery time window, flexibility, type of vehicle, accessibility, presence of bay, driver contribution, handling equipment. The planners handled these concepts (site, vehicle, client, order, driver and round), when building their planned transport rounds. The concepts and their attributes created resources and constraints, when performing a planning operation. Planners also integrated constraints involving regulations applicable to work, driving or the environment. However, these depended on concepts (e.g. downtown delivery is regulated in some cases): delivery times, type of vehicle authorized, parking location.... and through the planner's handling of the concepts that these constraints covered. Categorization of these constraints therefore corresponded to the concepts dealt with. Interview analysis allowed us to define 4 levels of constraint:

- Major constraints, for which it was imperative that the planner ensure their integration into his/her planning operation. These constraints arose from "regulation" or minimum characteristics to be implemented to fulfill the transport operation. In the former case, regulations were applicable, when they involve the highway code, the labor code, the environment or Heavy Goods Vehicle (HGV) driving. With regard to minimum characteristics to be implemented, these also represented major constraints because they could not be adapted. Thus, if the delivery site imposed maximum vehicle dimensions (e.g. underground passage access, hence maximum vehicle height and width), one major planning constraint would be the height and width of the vehicle to be used for this site

- Moderate constraints were to be integrated into transport round planning and their integration was indeed necessary. Adaptations could nevertheless be implemented, if needed.

- Minor constraints were more recommendations than necessities.

- "Absent" constraints are those that were not spontaneously signaled as planning constraints. Thus, health and safety determinants were associated with specific situations or points requiring vigilance and were not related to risks. These situations were to be carefully watched, when planning the transport round, but they did not constitute declared constraints for planners during construction of the schedule. 
Except for major constraints, managing levels of constraint remained dependent on the situation. For example, a moderate constraint could be relaxed in order to provide an acceptable planning solution. In a low activity situation, driver inexperience could be ranked at a level of moderate constraint and could lead to calling in a more experienced driver. In a high activity situation, round preparation was more constrained. Planners then had to abandon consideration of this constraint.

The card game allowed us to see that the constraints were prioritized by grouping them together or at least by processing aggregated attributes since constraints and attributes were not independent of each other. Type of vehicle, its capacity, driver's license requirement were aggregated and considered globally in some situations. In other situations, such as the "exceptional" request described in the remainder of this text, each attribute and constraint was considered separately.

The expression most often encountered in the interviews or in the card game with planners was "It depends!"..... it depended not only on the client, the site, the driver but also on the company strategy, the company's financial health, etc. The level of constraints and their prioritization were therefore contingent. Moreover, the level of constraints was variable, depending on the planner's knowledge of the situation; in cases involving a new client, an exceptional order or an unusual type of goods, all the constraints would be prioritized differently by globally considering their levels higher than usual. Under these circumstances, what would be a valid, balanced transport round in financial, ecological and health and safety terms? For the project industrial partners, a valid round was a round that, ideally, combined two components, two types of performance:

- Performance internal to the company: suitable usage, from a financial standpoint, of human and physical resources and of the delivery time. This usage was intended to generate a positive financial margin.

- Performance external to the company: adequate response to client requirements. This response constituted quality of service to the client.

The "valid" transport round therefore depended on proportioning the quality of service to clients located in the round, while controlling costs and profitability. These two components and their "proportioning" had to be weighted according to company strategy. Round validity was assessed independently of the "ecological" and "health and safety" dimensions. The project industrial partners integrated these dimensions into the balanced round. The balanced round depended on mobilizing human and physical resources that were adequate for the company's objectives. Nevertheless, this mobilization had to conserve a margin for maneuver in terms of managing clients and unforeseen events during round performance.

\subsection{Rating of STS Determinants by Sector Professionals}

It should be remembered that the planners described health and safety determinants with respect to situations and points requiring vigilance and not with respect to risks or constraints. Thus, site accessibility problems, complex loading/unloading locations, handling and stripping and unusual or extended working hours were all situations identified for their physical aspects. A new client, heavy traffic, complex 
infrastructures, an unforeseen wait at the client causing time-related stress were all situations identified as hazardous for mental health. Emotional aspects did not give rise to specific situation identification.

\section{The Questionnaire}

The findings presented are from the questionnaire's experimental stage with the project industrial partners (7 planners); they provide elements of information in terms of STS determinant rating. These elements need to be supported by data from the questionnaire's wide circulation. Two general issues were included prior to presenting the results based on factors causing difficulty or arduousness.

With regard to safety, defined by 4 items (theft and holdup, assault, accidents when stationary or driving), $57 \%$ of participants asserted that they took it into account by providing technical solutions such as secure vehicles (holdup and assault) and assignment to rounds based on driver skills and potential hazards. Planners, who did not integrate this aspect into their planning, asserted that this was dealt with by corridoring or watchmen at client sites to prevent assault, by driver training and compliance with regulations preventing accidents, when stationary or driving.

With regard to health, $87 \%$ of participants stated that they took this into account during planning by providing technical solutions to alleviate certain constraints (e.g. electrical pallet trucks), driver assignment (attention given to driver age, known health problems...) and order management (high volume orders broken down). One of the planners did not integrate health into planning because he considered health to be managed by applying regulations and by equipment selection by company management. Following these two general issues, more specific issues were raised (Table 1). These are based on physical, mental and emotional aspects.

\section{Physical Aspects}

These aspects were based on situations involving site access difficulties and handling situations. $87 \%$ of the participants considered that handling and site accessibility were factors causing difficulty and arduousness. However, all participants took them into account in their planning. Site accessibility-related difficulty was rated at between 5 and 7 on a 1-to-10 scale with 1 very low and 10 very high.

\section{Mental Aspects}

"Driving" and "Prolonged attention" were envisaged as mental aspects. With regard to these aspects, the planners considered that all their drivers were affected. Hence, these aspects were taken into account during planning and were rated between 4 and 8 with $42 \%$ rated 8 ).

\section{Emotional Aspects}

Assaults and relationship with the client were situations identified as causing emotional difficulties. All the planners reckoned that drivers were exposed to such situations. With regard to relationship with the client, emotional difficulty was "often" effective in $28 \%$ of cases, "sometimes" in $43 \%$ of cases and "rarely" in other situations. $71 \%$ of planners integrated this difficulty into their planning. However, this difficulty was rated moderate to low (between 1 and 5). 


\section{Other Difficulties}

The 7 planners referred to difficulties or situations considered tough:

- Lifestyle (sleep, food, adapting to variable work rhythms, etc.) was quoted 3 times with a rating of 9

- Meteorological conditions were quoted twice with ratings of 8 and 7, Traffic was quoted twice with a rating of 8 , Time-related stress (lateness) was rated 8 , Bay entry and driving maneuvers were rated 7

- Lack of knowledge of the client was a difficulty rated 5.

Physical, mental and emotional dimensions were all present within these "other difficulties".

\section{Discussion and Conclusion}

The findings of this study highlight that transport round planning activity is segmented, that situations involving dual tasks are usual and frequent, and that usage of tools is intensive and brief. Work intensity and information load handled by various tools are constants of the planner's activity. We also recall that planning is spread right across the entire daily activity.

Planners manage multiple constraints, which arise from outside the company or depend on decisions made by the company. The former are constraints related to regulations, infrastructures or clients. Constraints inherent to the company are related to the choice and sizing of the vehicle fleet, the strategy of the company and its human resources (drivers) for managing the activity. Constraints external to the company are considered major constraints to be overcome whatever the situation. Constraints inherent to the company have no status a priori; depending on the situation, they can be major, moderate or minor. Planners consider these constraints to be mutually dependent and they therefore deal with them globally. However, when the situation, context or demand is exceptional, constraints are prioritized differently and processed separately. With the exception of major constraints, prioritization cannot be performed a priori. It must be contingent on both the context and the situation.

It should be noted that employee health and safety aspects during planning were not spontaneously referred to during the study interviews. Furthermore, when the employees were questioned, they spoke mainly about situations requiring special care by the project industrial partners and not about exposures or risks. The physical dimension was referred to within this framework. When the mental and emotional dimensions were raised, they were not dismissed but were considered inherent to the driver's job or to the driver's responsibility. However, with the questionnaire, consideration of the health and safety dimension in planning was effective for a large majority of planners, even though a variability in dimension integration was noted: the emotional dimension being less integrated by planners. It is also the dimension that was rated as having a lower intensity. It is not because the health and safety dimension was not stated as being systematically integrated during planning that it was not necessarily taken into account. The planners considered that certain factors, such as the company's choice of handling equipment, vehicle fleet deployment, corridoring or compliance 
with regulations on driving time, safety training for drivers, etc., effectively meet the requirements of driver health and safety.

We also noted that the RFT context and the corporate strategy led planners to adapt constantly their management of constraints and consideration of the different dimensions. The next stage of this research will therefore be to focus on designing a compromise development system rather than a constraint prioritization system. Compromise development analysis conducted by planners during their activity would appear to represent an interesting route to preparing a delivery round that is both valid and balanced for industrial stakeholders.

\section{References}

1. Camman C, Fiore C, Livolsi L, Querro P (2017) Supply chain management and business performance: the VASC model, 1st edn. Wiley-ISTE, London

2. Joling C, Kraan K (2008) Use of technology and working conditions in european union. European foundation for improvement of living and working conditions, Luxembourg

3. Bilan de l'Observatoire social des transports (2013) Commissariat général du développement durable, service de l'observatoire et des statistiques

4. Wioland L (2013) Ergonomic analyses in the transport and logistics sector. Reflection on developing a new prevention approach: "Act Elsewhere". Accid Anal Prev 59:213-220

5. Apostolopoulos Y, Shattell MM, Soenmez S, Strack R, Haldeman L, Jones V (2012) Active living in the trucking sector: environmental barriers and health promotion strategies. J Phys Act Health 9:259-269 